\title{
DOCUMENTACIÓN Y ANÁLISIS ARQUITECTÓNICO EN EL PAÍS VASCO. ALGUNAS EXPERIENCIAS LLEVADAS A CABO EN ÁLAVA- ESPAÑA
}

\author{
(ARCHITECTURAL DOCUMENTATION AND ANALYSIS IN THE BASQUE COUNTRY. SOME \\ EXPERIENCES FROM ÁLAVA-SPAIN)
}

A. Azkárate, A. Fernández de Jáuregui, M. Nuñez

Fecha de recepción: 13-II-95

Área de Arqueología. Univ. del País Vasco

ESPAÑA

\section{RESUMEN}

Este articulo, que describe el trabajo desarrollado en el Pais Vasco, quiere ser reflejo -forzosamente breve-de una dinámica generada hace dos años (1993) en torno al Servicio de Patrimonio Histórico de la Dirección de Arquitectura y Urbanismo de la Diputación Foral de Alava, en colaboración con el Area de Arqueología de la Universidad del País Vasco.
SUMMARY

This article, which describes the work carried out in the Basque Country, seeks to be a-necessarily brief - reflection of a dynamics generated two years ago (1993) around the Historical Heritage Service of the Architecture and Building Office of the Diputacion Foral de Alava in collaboration with Archaeology Department of the Basque Country University.
La filosofía que ha guiado las tres intervenciones, a las que posteriormente se aludirá, está sustentada en un principio básico que se olvida con demasiada frecuencia en las actividades vinculadas al patrimonio arquitectónico. Nos referimos a la necesidad de tratar, de forma unitaria, tanto la estructura edificada como el contenido de su subsuelo ${ }^{1}$. Arqueólogos y arquitectos se han dado la espalda durante demasiado tiempo, ignorando los primeros el indudable paralelo existente entre los estratos arqueológicos soterradosy las sincronías y diacronías estructuralesy/o decorativas de un edificio mixtificado por la acción del hombre durante siglos, y no apercibiéndose los segundos de que la intervención restauradora en una construcción histórica (con sus limpiezas, recrecidos, demoliciones, saneamientos, etc.), posee unos efectos altamente destructivos que es preciso paliar con un riguroso proceso de documentación de carácter previo.

Esta concepción unitaria exige que la intervención, tanto en el yacimiento como en el propio edificio, sea sincrónica y esté articulada además por un mismo sistema de análisis.
Por lo que respecta a la parte más tradicional de las intervenciones, en nuestra experiencia se ha adoptado siempre el sistema estratigráfico de registro por contexto simple, de acuerdo con los planteamientos metodológicos expuestos por E.C.Harris. Para el estudio del edificio se ha aplicado el "análisis estratigráfico de construcciones históricas". Esta metodología de trabajo parte de la consideración del edificio como una prolongación en altura del subsuelo, dado que los elementos que los componen en ambos casos son producto de una estratificación arqueológica (aunque en muy diferente estado de conservación) y, como tal, producto de la actividad constructiva y destructiva y de transformaciones operadas por el hombre, además de las acciones debidas a agentes naturales. Su tratamiento por parte de cualificados especialistas en las páginas de este mismo número de INFORMES nos evita la tarea de extendernos en aspectos teóricos que conducirían seguramente a reiteraciones estériles. Del aprendizaje de uno de los firmantes (A. Fdz. de Jaúregui) con G.P. Brogiolo, de la lectura de la bibliografia existente (italiana casi en su totalidad) y de nuestra propia experiencia de campo ha 
resultado una praxis que no difiere sustancialmente de la manera de trabajar que se refleja en otros artículos que acompañan al nuestro. En este sentido, nos gustaría dejar constancia de la deuda contraída con L. Caballero Zoreda, alma mater sin duda de un equipo de arquitectos $\mathrm{y}$ arqueólogos que llevamos trabajando desde hace algunos años en la documentación y análisis de construcciones históricas. Con él hemos llevado a cabo un proceso de aprendizaje fecundo, contrastando nuestras experiencias con las suyas, discutiendo en positivo sobre un método de trabajo en proceso todavía de definición en algunos aspectos, enriqueciéndonos, en definitiva, con el magisterio de sus observaciones y consejos. Hacemos extensible también esta deuda a la Sección de Patrimonio Histórico de la Dirección de Arquitectura y Urbanismo de la Diputación Foral de Álava. El compromiso adquirido por el equipo que dirige el arquitecto J.I. Lasagabaster con la conservación del patrimonio edificado en Álava, y la seriedad y espíritu de renovación que acompaña a sus intervenciones, ha abierto las puertas a una colaboración entre diversos especialistas e instituciones (Servicio de Restauración de la propia Diputación, distintas Áreas de Conocimiento de la Universidad del País Vasco, CSIC., etc.) que multiplica, sin duda, la potencialidad y calidad de sus actuaciones.

A modo de ejemplo, recogeremos en estas páginas algunos breves apuntes sobre tres intervenciones recientes, todavía en curso de ejecución, con los cuales queremos reflexionar sobre la necesidad de un conocimiento previo del devenir constructivo del edificio para, evitando generalizaciones al uso, llegar a una comprensión de su historia real que coadyuve positivamente en la intervención restauradora llevada a cabo por los arquitectos. No se trata, por lo tanto, de resumir en pocas páginas las conclusiones científicas de las tres intervenciones (sería imposible, por otro lado), por lo que obviaremos los datos exigibles en cualquier memoria tales como el resumen de los resultados, los diagramas

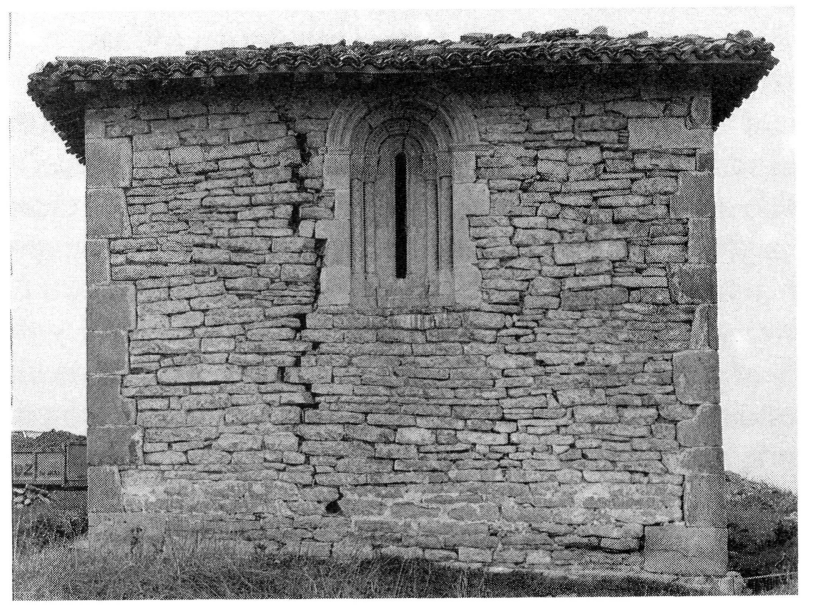

finales periodizados, los listados de elementos, planimetrías completas, etc. ${ }^{2}$ Los gráficos que acompañan al texto no son más que algunos ejemplos de la documentación gráfica que acompañará a los tres trabajos.

\section{Ermita de San Pedro de Quilchano (Argómaniz, Álava) ${ }^{3}$ (Figs. 1-9)}

San Pedro de Quilchano, a pesar de su sencillez y de la modestia de sus dimensiones, constituye un paradigma de indudable interés para la restauración de nuestro patrimonio histórico edificado. Considerada por la bibliografia como una "bella iglesia románica", el análisis y documentación de carácter arqueológico-arquitectónico llevado a cabo en ella ha demostrado que la fábrica actual responde,
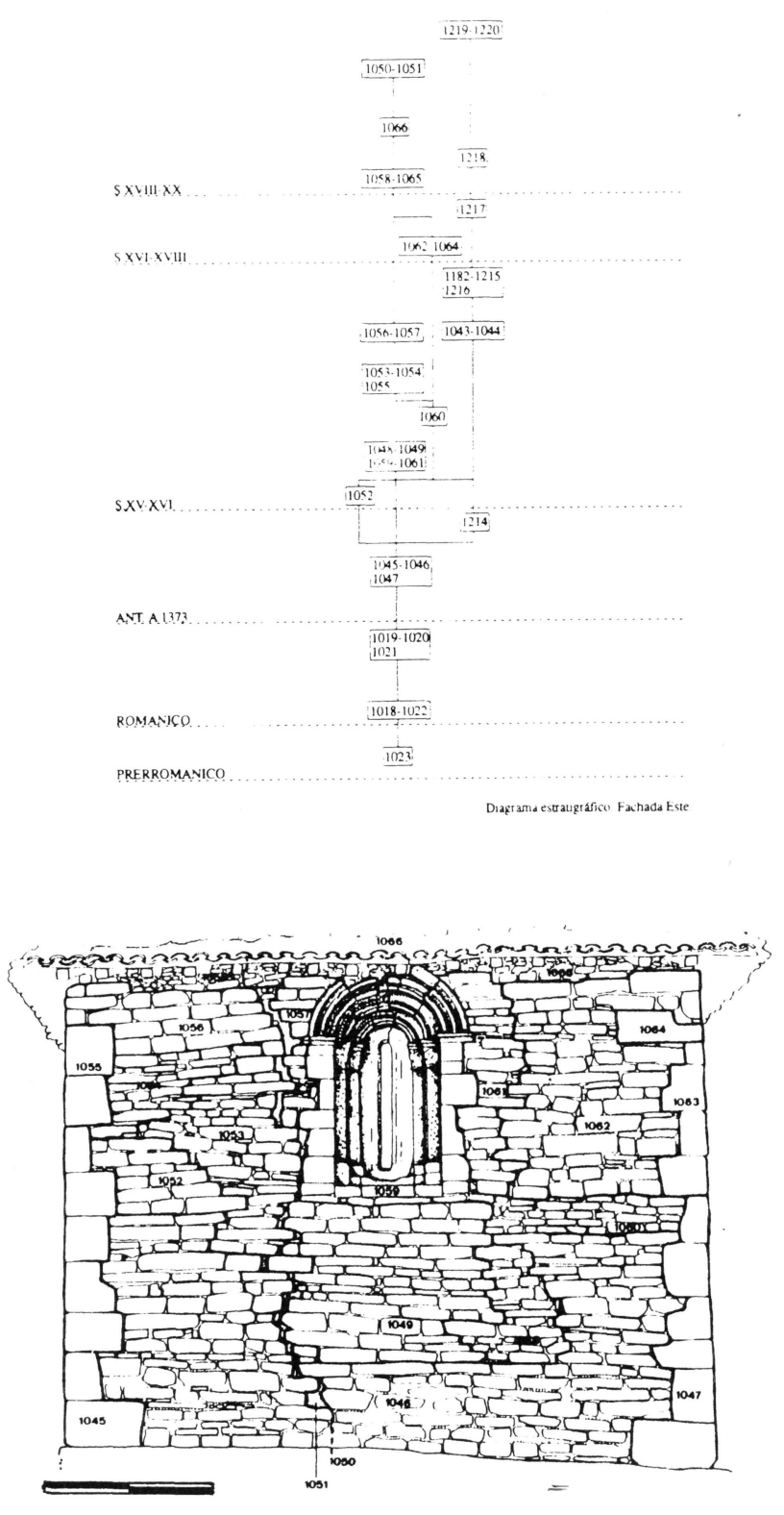

Figs.1 a 3.- S. Pedro de Quilchano. Fachada Este, documentación y diagrama estratigráfico.

(c) Consejo Superior de Investigaciones Científicas 
en realidad, a una edificación bastante posterior en el tiempo que conserva, no obstante, algunos elementos de período románico.

Determinadas concepciones de la Historia de la Arquitectura y de la Historia del Arte que tienden a valorar las construcciones en función, básicamente, de criterios de carácter estético, ha conducido a la creación de "edificiosmodelo" calificados globalmente dentro de tal o cual estilo artístico. Se olvida, de esta manera, que las edificaciones que contemplamos actualmente no son, en la mayoría de los casos, sino el resultado de sucesivas mistificaciones de carácter constructivo que sólo un detallado análisis estratigráfico de su fábrica puede identificar, individualizar y articular cronológicamente hasta permitir la comprensión de su historia real.

San Pedro de Quilchano pasaba, como queda dicho, por una pequeña iglesia rural de época románica, sugiriéndose incluso que sus pinturas murales pudieran pertenecer también a dicho período. Una primera observación in situ del edificio, sin embargo, nos condujo a sospechar de tal adscripción cronológica. Eran varias, en efecto, las razones que inducían a ello: los esquinales del NE. y SE. de la ermita estaban construidos con material reutilizado procedente de sepulturas exentas de período medieval (E.C. $1045,1047,1069,1080,1090)$, los vanos "románicos" mostraban señales evidentes de haber sido remontados de nuevo, etc.
Sin efectuar una excavación arqueológica en sentido estricto, se procedió a recuperar la planta de la primitiva iglesia, dando como resultado el descubrimiento de la cimentación de tres grandes contrafuertes al N. el acceso principal al lado $\mathrm{S}$. el desplazamiento de la zapata de cimentación al E., etc. Sintetizando la evolución constructiva de San Pedro de Quilchano a lo largo de los siglos, recogeríamos como más significativos los aspectos siguientes:

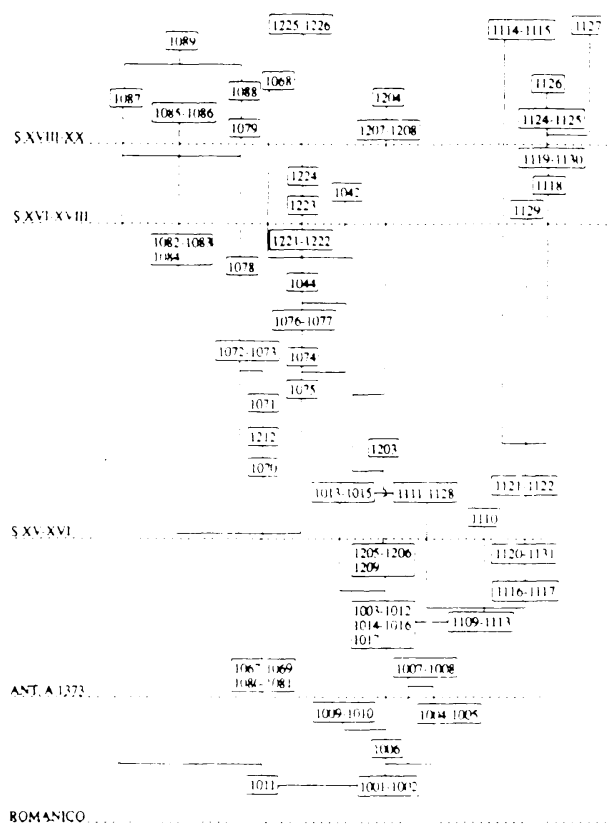

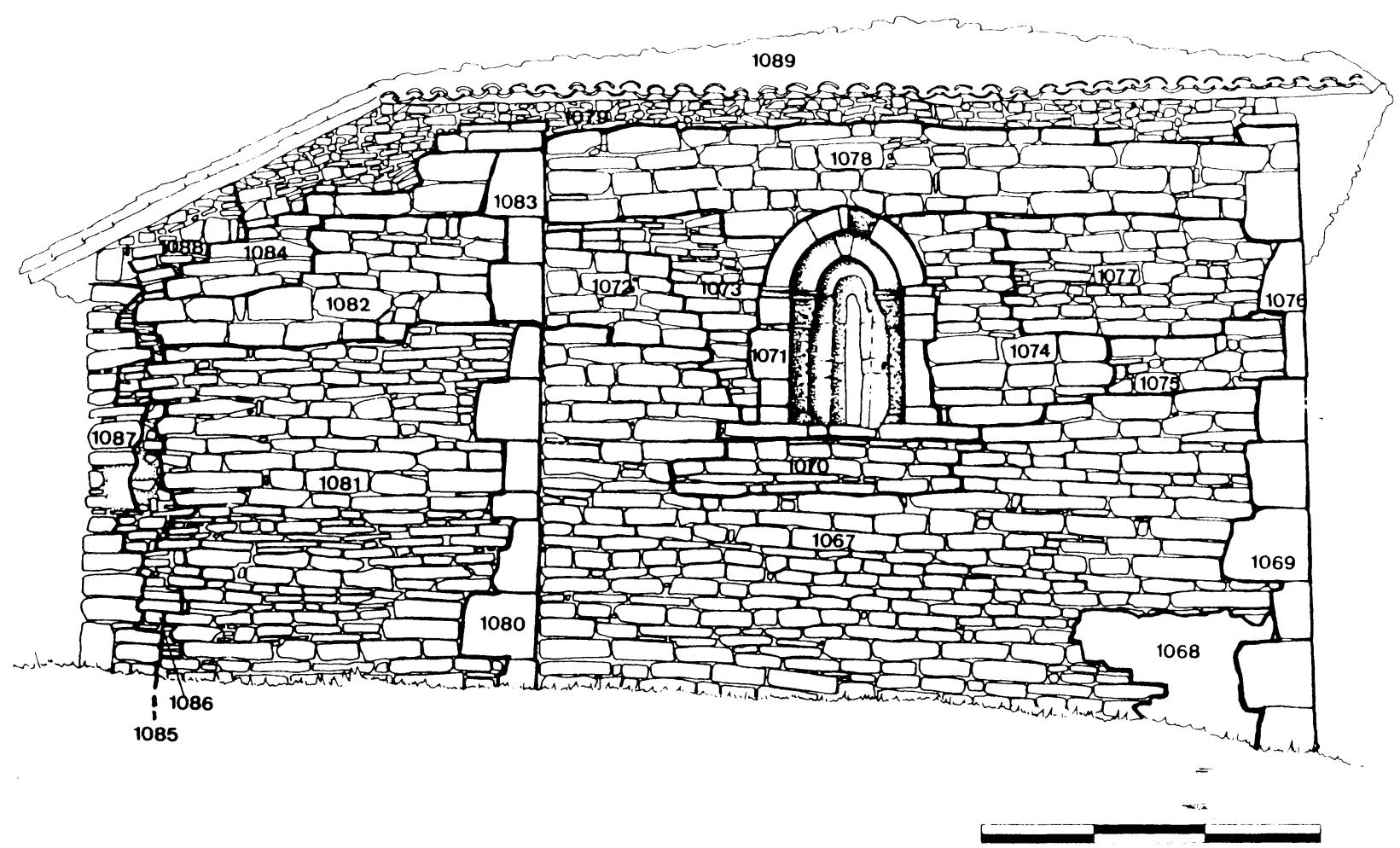

Figs. 4 y 5.- S. Pedro de Quilchano. Fachada Sur, documentación y diagrama estratigráfico. 
1. Primera fase. Románico (sigloXII) (Fig.7). Existió una primera iglesia románica ${ }^{5}$ de nave única y testero recto, con una sola puerta de acceso en su lado meridional y cubierta a dos aguas. De esta edificación conservamos solamente la zapata de cimentación y los dos ventanales principales remontados en época muy posterior, como se podrá observar.

2. Segunda fase. Reconstrucción del siglo XIV (Fig.8). Esta primera iglesia sufrió una ruina total al ceder el terreno sobre el que se asentaba por su ladera septentrional. La cimentación reventada de la fachada E., puesta al descubierto tras el control arqueológico efectuado, constituye un testimonio elocuente de aquel suceso. A comienzos del siglo XIV se reedifica la iglesia, respetando básicamente la planta primitiva. Ésta sufre, sin embargo, algunas modificaciones significativas: se añaden tres contrafuertes de tamaño desmesurado con ánimo de reforzar el lado septentrional del edificio, el más susceptible sin duda de sufrir nuevos corrimientos por su proximidad a la ladera. Se abre una nueva puerta a los pies del templo y se amplía el acceso principal. Las columnas torales proceden de esta segunda fase. Es en este momento, también, cuando se reutilizan sarcófagos exentos de arenisca para la provisión de los esquinales de la nueva iglesia. El muro S. es el más representativo de este período por el volumen de obra conservada, siendo su cara interior la única que conserva elementos decorativos. Nos referimos concretamente al pequeño vano geminado construido con elementos románicos y rematados por sendos arquillos apuntados, circunstancia que adquiere mayor sentido desde la cronología propuesta para esta fase.

3. Tercera fase: transformación en ermita (Fig.9). El abandono de Quilchano como lugar habitado a partir de 1337 debió afectar profundamente a la conservación del edificio. En un momento indeterminado?, la segunda iglesia volvió a sufrir un nuevo derrumbe. Estas ruinas sucesivas de la iglesia sólo encuentran explicación en la propia ubicación del edificio, emplazado sobre un pequeño cerro con graves problemas de corrimientos de tierras en su lado septentrional. Convertido el lugar de Quilchano, desde hacía mucho tiempo ya, en despoblado, la reparación de los daños fue mucho más modesta, reduciéndose notablemente la planta de la iglesia derruída y convirtiendo a ésta en una sencilla ermita rural. La nueva etapa constructiva prescindió de gran parte de la nave y se limitó básicamente a su cabecera, recreciendo los paramentos conservados (E.C. 1048, 1049, 1052, 1053, 1054, 1055, $1056,1057,1060,1061,1070,1072,1073,1074,1075$, $1076,1077,1078,1082,1083,1084,1093,1097,1098$, 1099, 1102), modificándolos ligeramente en algunas de sus hiladas hasta alcanzar la altura deseada, y remontando de nuevo los vanos románicos de las fachadas oriental (E.C. 1059) y meridional (E.C. 1071). Por lo demás se reutilizaron los materiales de la etapa anterior, tanto en las cadenas de refuerzo de las esquinas (E.C. 1055, 1063,
$1069,1076,1080,1083)$, como en el resto de los paramentos.

En el interior se introdujeron también nuevos elementos, siendo los más destacables el vano abierto en el interior del muro N. y los apeos adosados a las esquinas suroriental y nororiental, en los que apoyaría una bóveda de crucería de materiales ligeros, muy probablemente lígneos, y de cuya existencia se conservan todavía testimonios significativos

Ignoramos el sistema de cierre que recibió la fachada occidental, pero la existencia en este lugar de un pequeño alineamiento de piedras sobre las que posteriormente se construyó el pretil del pórtico actual, sugiere la posibilidad de que se tratase no de un muro corrido, sino de un cierre de madera similar al de otras muchas ermitas de nuestro entorno inmediato. Ello parece confirmarse por un dato documental de 1721 en el que se menciona un pórtico abovedado al que haremos referencia más adelante.

4. Cuarta fase: ermita actual: Las menciones documentales conservadas en los Libros de Fábrica que se refieren a reparaciones efectuadas en Quilchano se multiplican a partir del siglo XVIII. Puede decirse que el aspecto actual de San Pedro es el resultado de todas estas reparaciones. Conservamos una mención documental muy significativa del año 1721. Por averse reconocido que el sitio a manera de portico que esta a la entrada de la Hermita de San Pedro de Quilchano esta con su bobeda mucho mas decente para Hermita que el sitio que hoy sirve de tal... se ordena quel dho portico se cierre hasta la boved a y sirva de Hermita... No sabemos, empero, cuándo se ejecuta esta orden por no conservarse referencia alguna en los Libros de Fábrica Debió de llevarse a cabo, no obstante, entre 1721 y 1757 o poco más tarde, pues en esta última fecha se inicia la venta masiva de material constructivo. Entre 1757 y 1790 se venden más de 500 carros de piedra que, procedente de las ruinas de la nave de la antigua iglesia parroquial, debía permanecer amontonada in situ desde hacía dos o tres siglos. De 1761 se conserva también otra mención significativa que se refiere a los costos derivados de componer $y$ allanar la entrada. En torno a estas fechas, por lo tanto, Quilchano fue adquiriendo el aspecto que ofrece actualmente. Las antiguas ruinas desaparecieron hasta los cimientos con la masiva venta de piedra, hasta el punto de sustraer a la memoria histórica el recuerdo de la planta primitiva que sólo los recientes controles arqueológicos han podido recuperar. Se levantó el cierre actual de la ermita (E.C. $1140,1155,1156 \ldots$ ), se prescindió de la espadaña y se procedió a la reforma más significativa, reduciendo la altura de la ermita construida durante la tercera fase: desapareció, por tanto, la antigua bóveda lígnea y se construyó una nueva de lunetos desmontada en 1993 durante el transcurso de los actuales trabajos de restauración. Para la construcción de estā segunda bóveda -de menor altura- fue necesario desmontâr los apeos de la anterior y crear nuevas ménsulas de apoyo. 


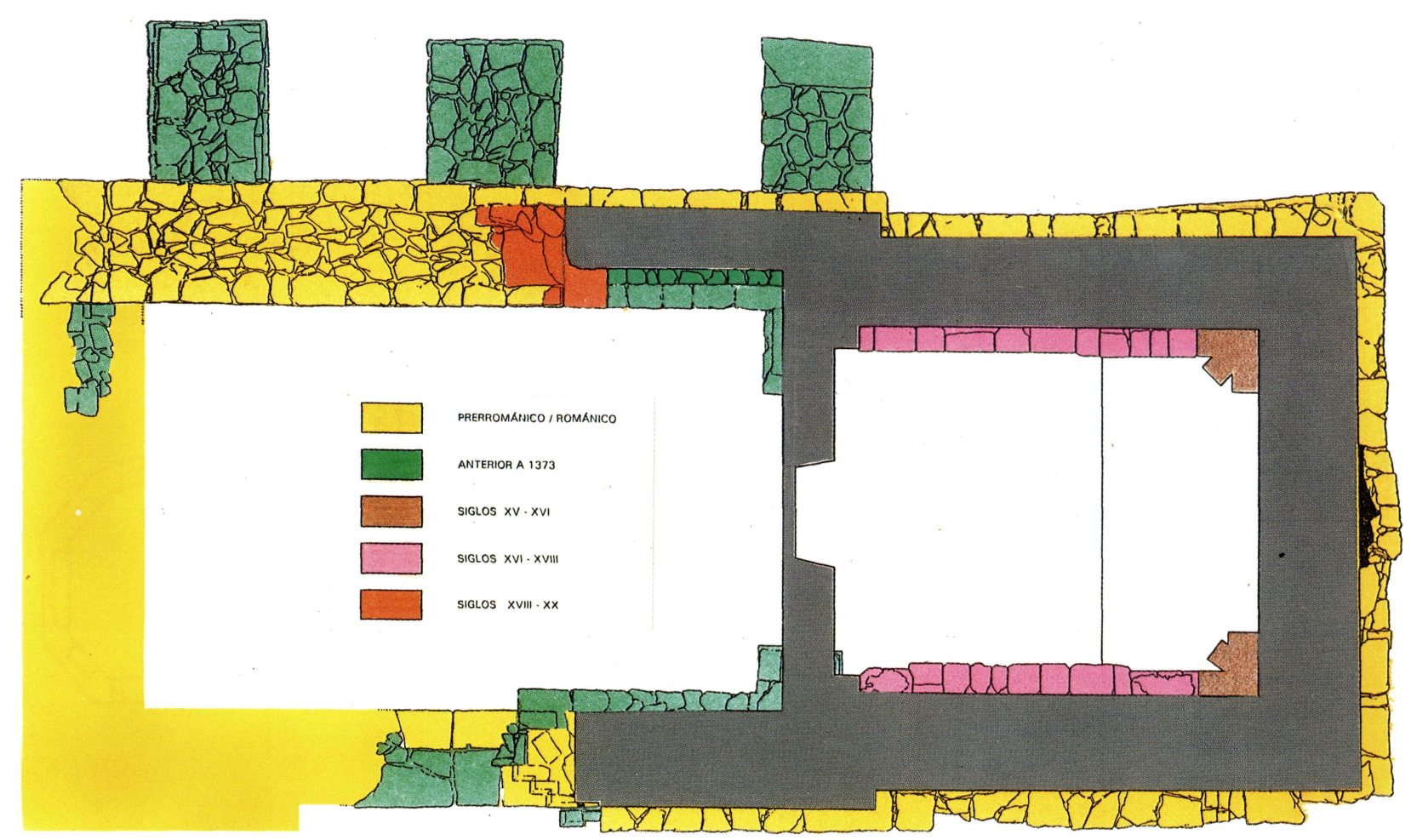

Figs. 6 a 9.- S. Pedro de Quilchano. Planta con las fases constructivas y esquemas volumétricos de los restos correspondientes respectivamente a la construcción románica y a las reconstrucciones anterior a 1373 y al s. $X V / X V I$.

San Pedro de Quilchano siguió siendo objeto de reparaciones diversas $(1783,1813,1816$, etc. $)$. A ellas responden la construcción de los últimos levantes que cierran el espacio entre las vigas (E.C. 1058, 1065, 1079, 1096), la reparación del frente de los laterales del pórtico (E.C. 1087, 1105), la pavimentación de ladrillo (E.C. 1038) y las sucesivas capas de pintura azulada y verde que cubren parciamente las etapas pictóricas más antiguas, las últimas de las cuales sabemos -por información de un lugareñofueron efectuadas a mediados de este último siglo.

\section{Iglesia del Santo Cristo (Labastida, Álava) ${ }^{8}$ (Fig. 10)}

La ermita del Santo Cristo de Labastida venía siendo objeto de diversas obras de consolidación y restauración de cubiertas en el marco del convenio que, para la conservación y restauración del Patrimonio Cultural edificado, propiedad de la Iglesia Católica, suscribieron en su día el Departamentode Relaciones con las Entidades Locales y Urbanismo de la Diputación Foral de Álava y el Obispado de Vitoria. En este contexto, una intervención no controlada y ajena a la dirección de las obras provocó el levantamiento del pavimento, afectando gravemente al contenido arqueológico del subsuelo en un $40 \%$ de la totalidad del espacio eclesial: bastantes tumbas excavadas en roca quedaron al descubierto, la prensa hizo públicos ciertos "trofeos" (cálices y patenas) y el resultado final fueron cientos de huesos desparramados por todo el templo.

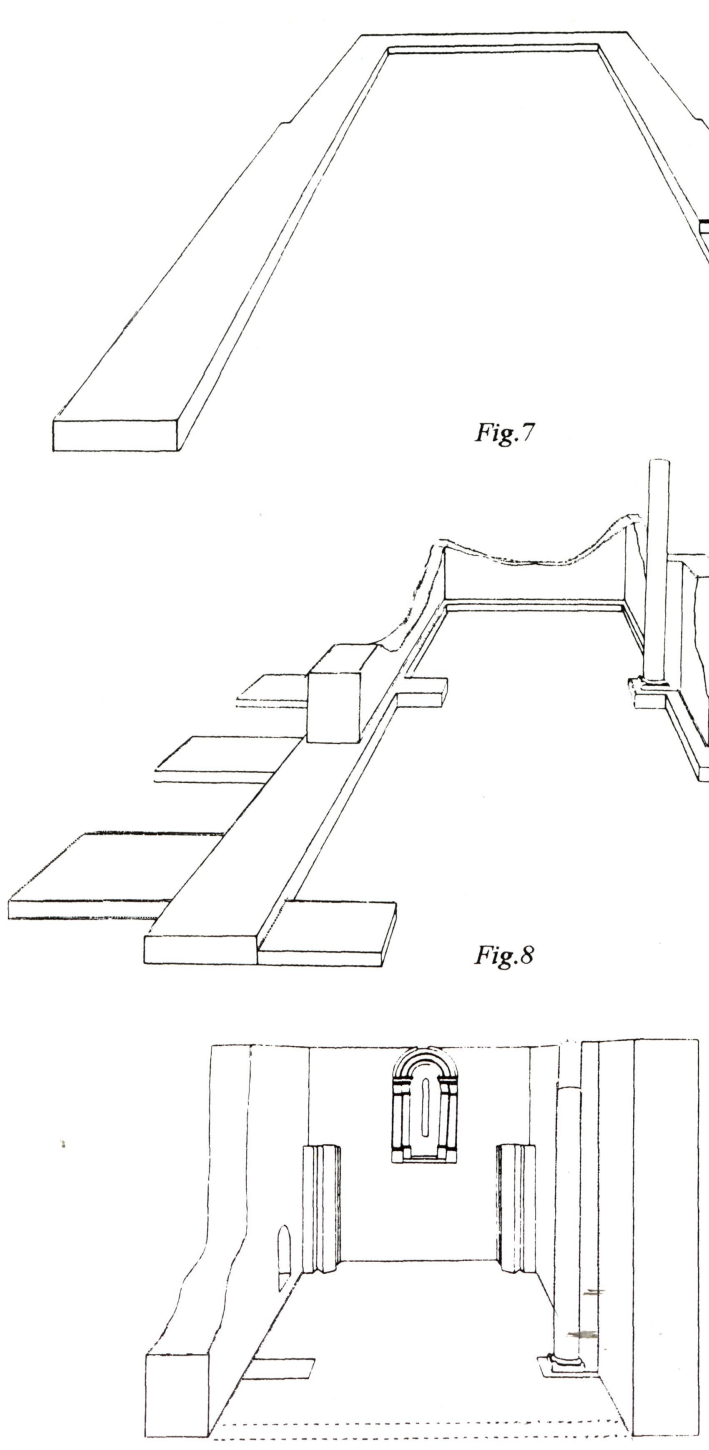

Fig.6

c) Consejo Superior de Investigaciones Científicas 


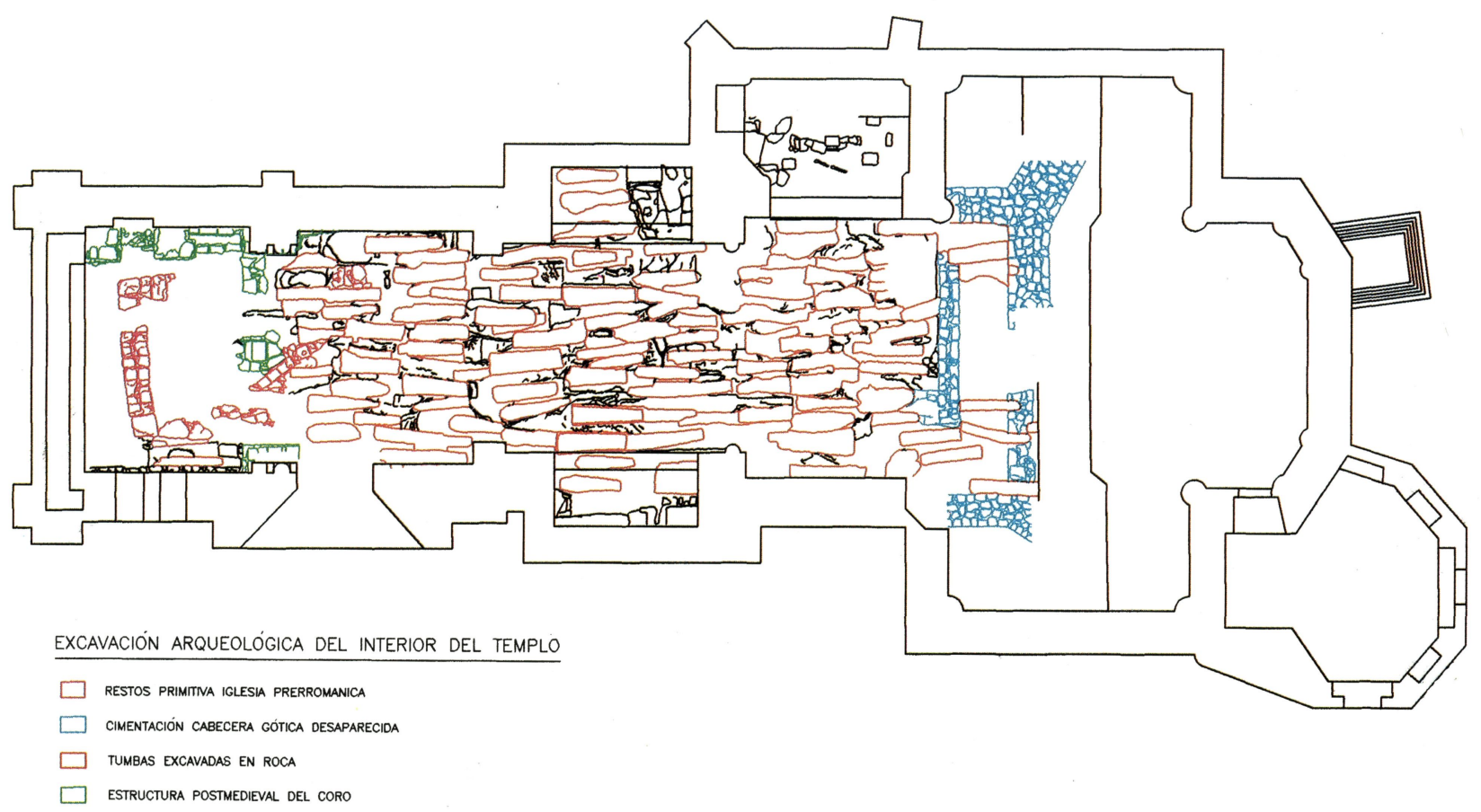

Fig.10.- Santo Cristo de Labastida. Planta.

Cumplimentados los trámites necesarios -adjudicación por concurso público y permisos- se procedió a una intervención arqueológica de urgencia, bajo la dirección de A. Azkárate y la participación de profesores y colaboradores del Área de Arqueología de la Universidad del País Vasco. La financiación, en su integridad, corrió a cargo del mencionado departamento foral, quedando su supevisión en manos de J.I. Lasagabaster.

Tras la remoción incontrolada del pavimento, y antes de nuestra intervención, los enterramientos que quedaron a la vista ya permitían observar que había sepulturas excavadas en roca de determinada tipología que cortaban a otras de tipología distinta. Se apreciaba, por lo tanto, una primera diacronía bastante elocuente por sí misma. La desigual orientación de algunas de estas tumbas respecto al eje axil del templo actual, estaba sugiriéndonos, además, la existencia de un recinto eclesial anterior -prerrománico por lo tanto- ya desaparecido. Desde un principio, en consecuencia, abrigamos la esperanza de dar con las cimentaciones del primitivo santuario.

Perfectamente observables, en todo el conjunto del Santo Cristo, se apreciaban además estructuras pertenecientes a períodos diferentes. Toda la bibliografía que se ha ocupado de este magnífico conjunto ha querido ver en él únicamente dos momentos: una iglesia románica cuya cabecera habría desaparecido, y una ampliación gótica posterior. La realidad, sin embargo, iba a ser mucho más compleja, como veremos.

\section{Avance de los resultados}

"Claramente se distinguen en su fábrica exterior dos construcciones de diversos estilos y épocas, románica y muy antigua la una y gótica la otra, debida esta segunda a una ampliación del templo, que ocasionó la pérdida para siempre del ábside del edificio primitivo"'. Esta opinión ha sido recogida sistemáticamente por cuantos se han ocupado de la ermita del Santo Cristo. Hoy en día podemos afirmar, sin embargo, que la historia de este monumento alavés es bastante más rica de lo que comúnmente se ha supuesto.

1.Primera fase. Prerrománico: Como preveíamos antes de nuestra intervención, tuvimos la fortuna de detectar la existencia de un pequeño templo prerrománico cuya cimentación se ha conservado sólo parcialmente. En torno suyo existió una necrópolis de tumbas excavadas en roca, algunas de las cuales todavía se conservan, destacando una de carácter antropomorfo que acota perfectamente el lado meridional de esta primitiva iglesia. La modestia de los restos conservados no empañan la importancia de un hallazgo que confirma la existencia, en Labastida, de un núcleo de poblamiento muy anterior a la carta foral ${ }^{10}$.

2.Segunda fase. Románico: La iglesia prerrománica se arrasó totalmente, levantándose sobre su misma ubicación -aunque con mayores dimensiones y una orientación ligeramente distinta- un nuevo templo románico del que conservamos en alzado gran parte de su planta basilical, una magnífica portaday diversos canecillos reubicados en período gótico y que debieron pertenecer a una cabecera románica actualmente desaparecida y de la que tampoco ha perdurado cimentación alguna. 
3.Tercera fase. Primer gótico: Durante el siglo XIV, probablemente, se acometió una nueva e importante ampliación gótica que ha pasado desapercibida a cuantos estudiosos se han ocupado del Santo Cristo, a pesar de que existían-y existen- suficientes testimonios de su existencia en los paños tanto exteriores como interiores de la fábrica actual. Fue, sin duda, un importante templo-fortaleza para cuya construcción se recrecieron notablemente los alzados románicos, rematándolos con un almenado que debía ofrecer al conjunto -bastante más corto que el actual- un impresionante aspecto. La existencia de esta iglesia, constatable a través del análisis estratigráfico de sus paramentos, ha recibido una espectacular confirmación arqueológica al haberse descubierto, bajo el pavimento del crucero actual, su cabecera de testero recto reforzado con sólidos contrafuertes oblicuo al exterior y una pequeña cripta bajo el espacio presbiterial. Este templo-fortaleza sufrió un devastador siniestro cuando agonizaba el siglo XV o muy a comienzos de la centuria siguiente, dato éste que hemos podido constatar -entre otros argumentos- por la existencia de un importante nivel de incendio fechado por hallazgos numismáticos de los RR.CC.

4. Cuarta fase. Gótico tardio: Inmediatamente, quizá dentro del primer cuarto del siglo XVI, se procedió a la reconstrucción del Santo Cristo. Se cerraron los merlones, rematándose el antiguo almenado con el acornisamiento actual y privando al conjunto del aspecto indudablemente militar que anteriormente tuvo. Pero la reforma más importante tuvo lugar en la cabecera, construida según los criterios estéticos propios del gótico tardío. Más adelante se fueron añadiendo diversos anexos hasta conseguir la configuración que actualmente ofrece la iglesia del Santo Cristo.

\section{Parroquia de San Román (Tobillas, Álava) ${ }^{11}$ (Figs. 11-} 21)

El mal estado de conservación de la iglesia de San Román de Tobillas y la ruina parcial de su cubierta condujo al inicio de las necesarias obras de restauración por parte de la Sección de Patrimonio Histórico del Departamento de Arquitectura y Urbanismo de la Diputación Foral de Álava. Apenas iniciadas aquéllas, fuimos requeridos por los arquitectos J.I. Lasagabaster y J. Arregui para emitir un informe previo sobre el valor histórico del edificio que, una vez más, venía siendo considerado como una parroquia rural construida en estilo románico, pero que presentaba suficientes vestigios como para merecer una atención detallada. La sensibilidad de los arquitectos mencionados resultó de nuevo definitiva para abordar una intervención con los criterios más rigurososos, posibilitando un descubrimiento verdaderamente importante que, de otra manera, hubiera pasado desapercibido y evitando que durante el proceso de restauración quedara oculta -quizá irreversible-

(c) Consejo Superior de Investigaciones Científicas

Licencia Creative Commons 3.0 España (by-nc)
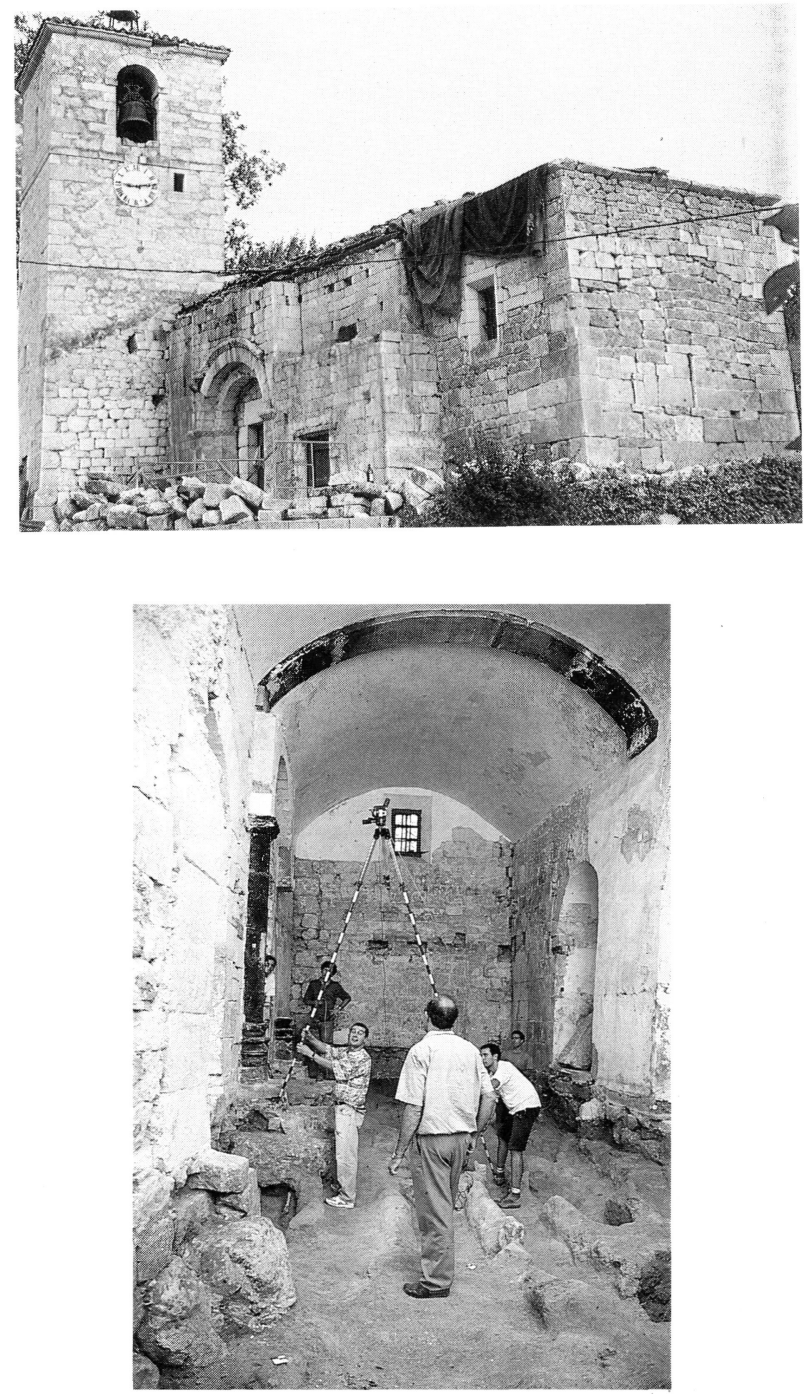

Figs.11 y 12.- San Román de Tobillas. Vista exterior y toma de pares fotogramétricos en su interior.

mente- una información inestimable para la historia de la arquitectura religiosa.

Los trabajos efectuados han demostrado, en efecto, la gran antigüedad de la parroquia de San Román de Tobillas hasta el punto de poder considerarla como la decana de las iglesias edificadas en la Comunidad Autónoma del País Vasco. Un análisis provisional efectuado por A. Azkárate y L. Caballero Zoreda a petición, como queda dicho, de los arquitectos restauradores permitió descubrir varias etapas constructivas: una primera, circunscrita a la zona del ábside, con testimonios significativos de haber estado cubierta por una cúpula de toba sobre pechinas; una segunda, de aparejo diferente, que conservaba un vano y paños significativos de su paramento original en los lados meridional y occidental del aula; una tercera fase constructiva, correspondiente a período románico, con abundantes elementos decorativos, muy alterados y descontextualizados debido a la ruina sufrida por el edificio en época posterior; 


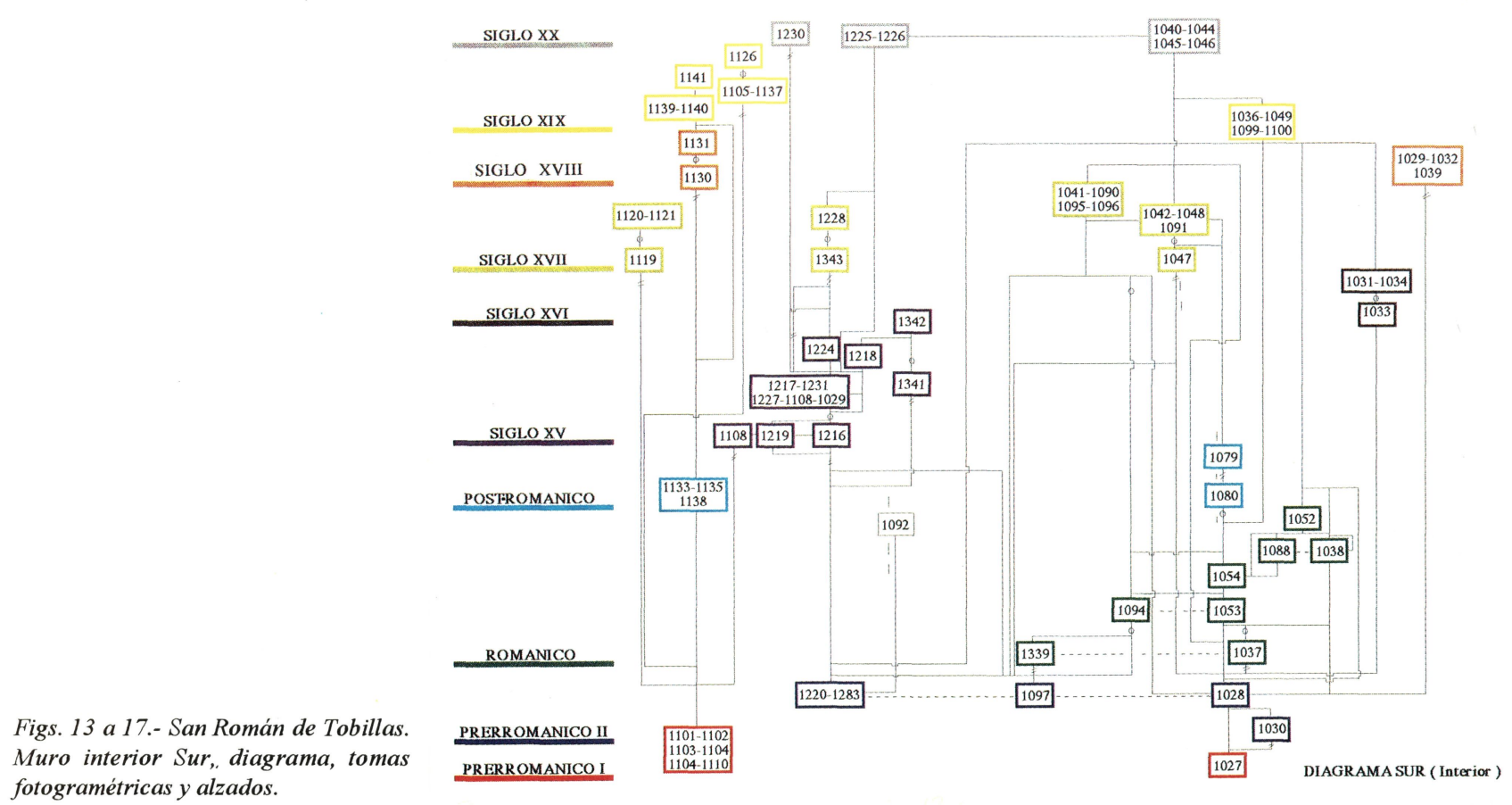

y varias fases más, finalmente, pertenecientes a intervenciones de época moderna y contemporánea.

De por sí, esta secuencia resultaba del máximo interés, viéndose acrecentada además por la antigua mención documental que recoge la fundación de Tobillas como iglesia monástica en el año $822^{12}$, su restauración a comienzos del siglo X a cargo del presbítero Vigila(según epígrafe procedente de la misma iglesia y conservado en la actualidad en el Museo de Arqueología de Alava) ${ }^{13}$ y el descubrimiento en el transcurso de las obras de un nuevo epígrafe de clara paleografía mozárabe, todavía in situ. Todo ello-varias fases prerrománicas, unaiglesia románica, reformas posteriores $y$, sobre todo, la posibilidad de fechar documentalmente las fases más antiguas- convertía a Tobillas en un monumento excepcional y en la mejor de las síntesis de arquitectura religiosa conservada no sólo en Álava, sino en el conjunto del territorio vasco.

La existencia de restos de una cúpula sobre pechinas en una de sus etapas primitivas relacionaba además este edificio con un grupo de iglesias del norte peninsular, fechadas todas ellas a comienzos del siglo $\mathrm{X}^{14}$. La de Tobillas es la primera que se conoce en el País Vasco y, por lo tanto, la más septentrional del grupo hasta la fecha, lo que permite preguntarse hipotéticamente si pudiera pertenecer al núcleo desde el que se expandió esta novedad arquitectónica, entonces extraordinaria. Por todo lo dicho, resultaba del máximo interés su estudio científico y la conservación y lectura de las huellas que de ella habían conservado.

Ante esta doble importancia patrimonial y científica, se aconsejó la interrupción de las obras mientras no se (c) Consejo Superior de Investigaciones Científicas Licencia Creative Commons 3.0 España (by-nc) efectuase un trabajo previo de documentación y análisis y se tomasen las medidas oportunas tras una reflexión serena en la que deberían participar diversos especialistas coordinados por el Serviciode Patrimonio Histórico de la Dirección de Urbanismoy Arquitectura de la Diputación alavesa. Los pasos a seguir, según común acuerdo, fueron los siguientes: $1^{\circ}$ ) excavación arqueológica del interior de la iglesia; $2^{\circ}$ ) documentación exhaustiva de la fábrica del templo, a elaborar por medio de la fotogrametría analítica informatizada (Figs. 12 y 21); $3^{\circ}$ ) análisis estratigráfico del edificio ("lectura de alzados") en coordinación con los trabajos de limpieza, descubrimiento y apertura de muros y vanos y de consolidación de pinturas; $4^{\circ}$ ) restauración de la iglesia, que deberá proyectarse teniendo en cuenta las conclusiones ofrecidas por los estudios previos, de modo que sea lo más respetuosa posible con todos los restos llegados a nosotros, poniendo en valor las distintas etapas y permitiendo la comprensión didáctica de los distintos períodos constructivos (Fig.11).

De estas cuatro fases de actuación, la primera de ellas se llevó a a cabo en verano de 1994 por un equipo del Área de Arqueología de la Universidad del País Vasco. Finalizada la excavación arqueológica se procedió inmediatamente a la toma de datos para la restitución fotogramétrica, cuyos resultados se entregaron a comienzos de octubre. La documentación planimétrica por fotogrametría, con obtención de un modelo digital tridimensional tanto de la excavación arqueológica como del conjunto de la iglesia corrió a cargo de Pablo Latorre y Leandro Cámara, arquitectos. Con la fortuna de disponer de una planimetría de gran calidad, el equipo de A. Azkárate procedió al análisis estratigráfico del conjunto arquitectónico (subsuelo y estructura), 

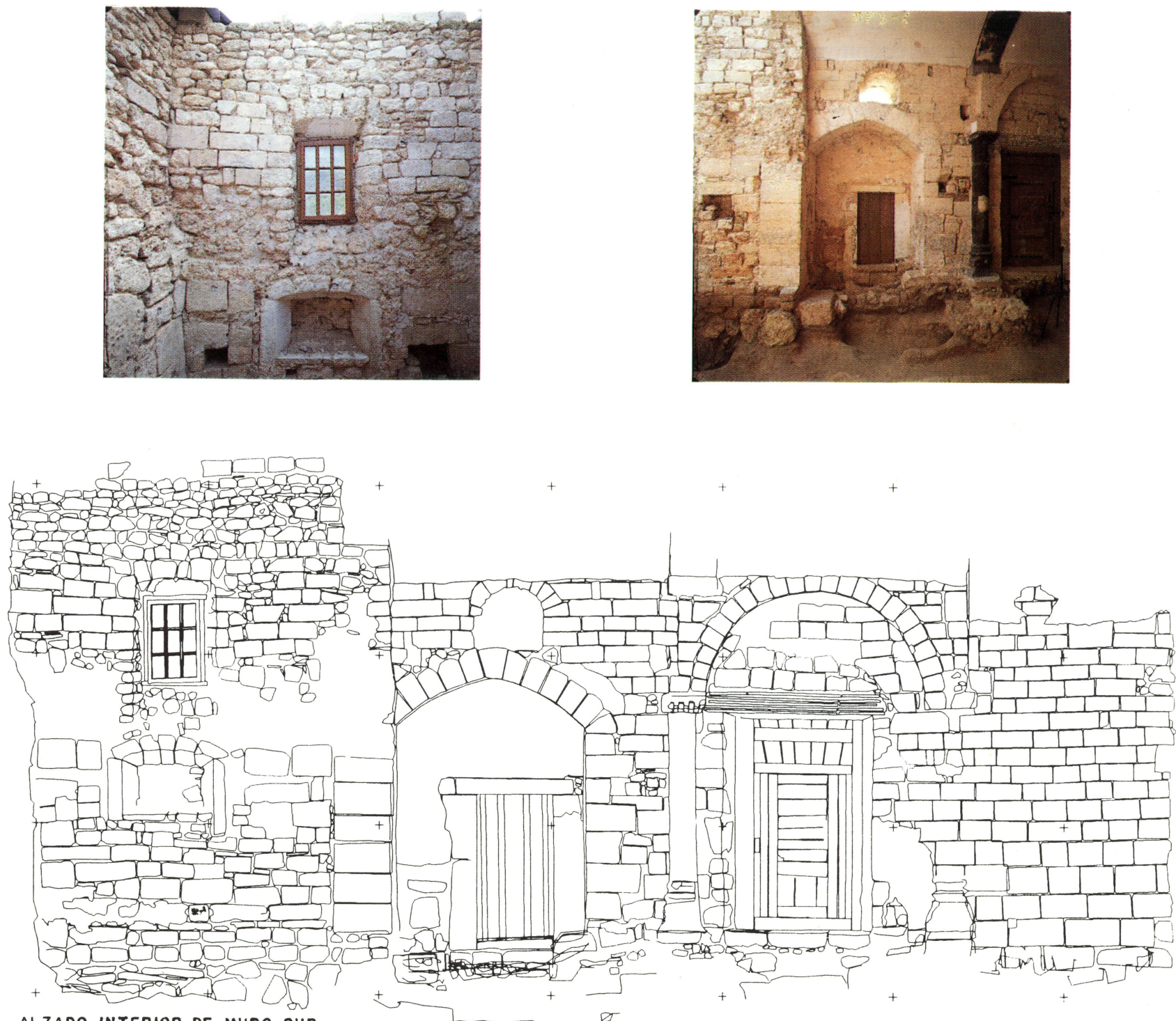

ALZADO INTERIOR DE MURO SUR e

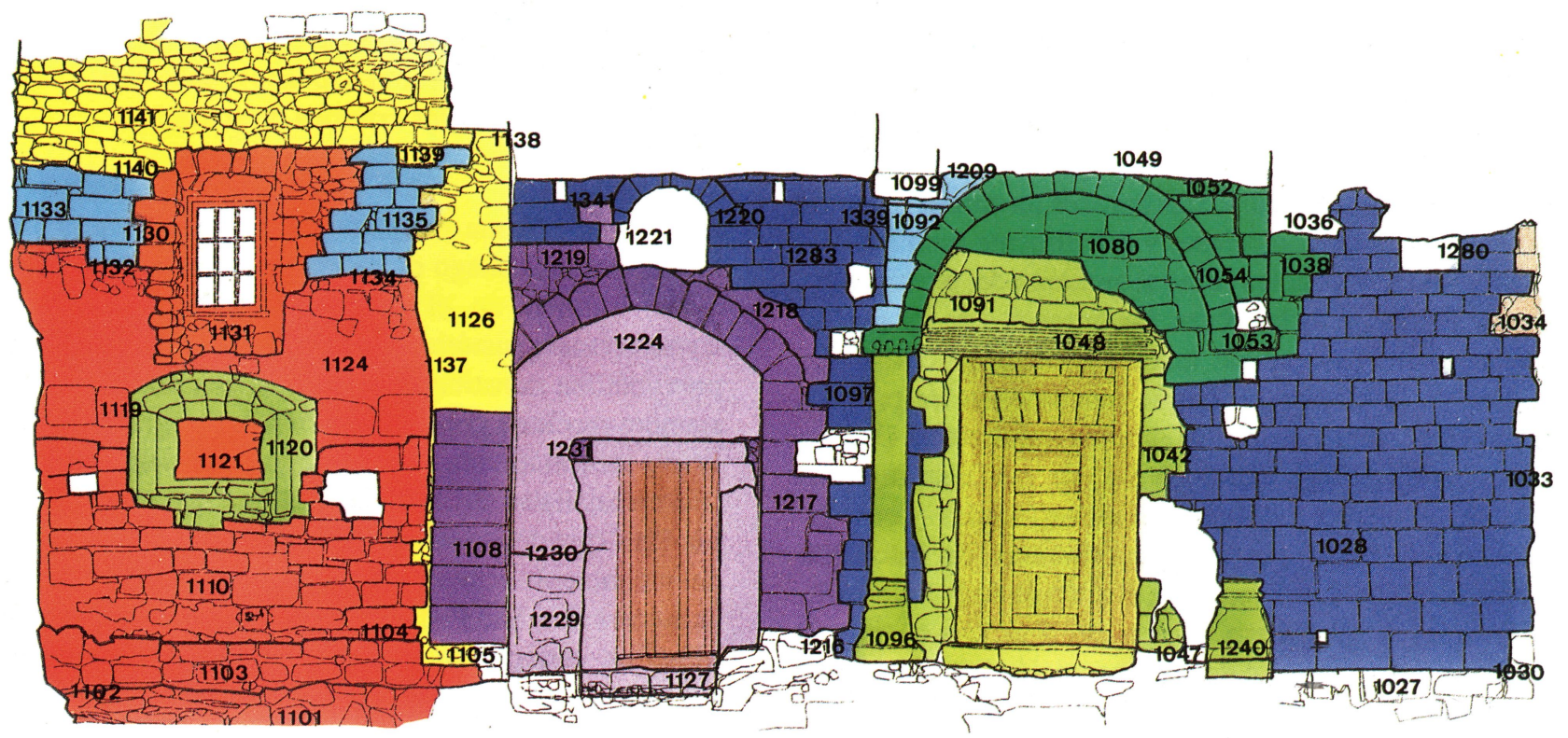


estando -cuando se escriben estas líneas- a punto de entregar las conclusiones definitivas. En breve se llevarán a cabo las primeras reuniones con los arquitectos J. I. Lasagabaster y J. Arregui con el objetivo de diseñar los criterios que habrán de guiar su proyecto de restauración del edificio.

\section{Valoración final}

Si tuviéramos que resumir en pocas palabras lo que consideramos esencial de todocuanto hemos venido comentando, habría que recordar de nuevo el alto riesgo de cualquier intervención restauradora en un edificio mixtificado por el tiempo, concebido como documento histórico y poseedor, por tanto, de una rica información que habría que respetar en grado máximo. Tantas veces ha sido repetida que se ha convertido ya en lugar común aquella vieja metáfora que comparaba el trabajo de un arqueólogo con el conocimiento de un librocuyas páginas el lector quemaba según la lectura fuera avanzando. Aunque no parece que los arqueólogos hayamos aprendido demasiado del ejemplo, a juzgar por la insistencia y alegría con las que se excavan yacimientos de todo tipo, también es cierto que existen todavía arquitectos no conscientes del carácter inevitablemente "destructivo" de su trabajo y que proyectan restauraciones en edificios de indudable valor histórico pensando que un pequeño capítulo encargado a algún joven licenciado en Historia o en Arte -casi inevitablemente en paro- es suficiente para cumplir con sus obligaciones respecto al carácter monumental del edificio. La documentación previa de un ejemplar arquitectónico que va a ser objeto de restauración debería de ser, por lo tanto, una obligación plenamente asumida por los profesionales que se dedican a ello. El contenido de los artículos que se recogen en este número apuntan todos en esta dirección

Sospechamos, sin embargo, que haríamos un flaco favor al método propuesto si lo defendiéramos únicamente como un instrumento para el conocimiento histórico de un edificio. Siempre habrá mentes pragmáticas a las que esto del conocimiento histórico les parezca un entretenimiento intelectual propio de ociosos y difícilmente asumible por motivos tan razonables como el aumento del presupuesto, la ralentización de las obras, las urgencias de los plazos, etc. Pensamos, en cambio, que el método propuesto tendrá futuro en la medida en la que resulte rentable para los proyectos y objetivos de los propios arquitectos. Cuando éstos se aperciban, por ejemplo, de que determinadas patologías estructurales puedan ser explicadas -y corregidas, por lo tanto- por el descubrimiento de patologías históricas (cfr., a este respecto, el artículo de P. Latorre, L. Cámara y L. Caballero, supra, pp 5 ss.), o cuando al término de un proyecto de documentación bien ejecutado, el arquitecto reciba un informe serio y preciso que facilite sus decisiones finales, tan delicadas y comprometidas muchas veces.
Son diversos, sin embargo los problemas que todavía han de superarse para que esta dinámica que proponemos se generalice. Algunos-a los que nos acabamos de referir-son conceptuales o de mentalidad. Otros, todavía, son estrictamente metodológicos: cuestiones como la propia denominación del sistema de trabajo ${ }^{15}$, el diseño preciso de un utillaje hermenéutico específico, el dificil tema de la publicación de los resultados, etc. constituyen materias que serán objeto de debate en un futuro próximo. No quisiéramos silenciar tampoco otros obstáculos de orden práctico con los que hemos topado en nuestra experiencia concreta. Uno de ellos -y no pequeño precisamente- es el de la coordinación entre los diversos especialistas que participan en el proceso de documentación del edificio. Recordamos, por ejemplo, el problema planteado con la restauración de las pinturas murales que conservan muchas de nuestras iglesias -aquellas que no padecieron la litolatría de los años setenta- y con los sucesivos enlucidos que muchas veces las cubren. No siempre resulta fácil que los restauradores intervengan antes de proceder a la toma de los pares fotogramétricos -aunque resultara sumamente interesante el hacerlo-, con lo que ello supone de pérdida de información importante para la restitución fotogramétrica.

Sería deseable, en este sentido, iniciar el proceso con la participación de un documentalista que proceda al vaciado sistemático de la información que sobre el edificio se conserve en los distintos archivos (actas, acuerdos, libros de mayordomía, libros de fábrica, etc.). La experiencia nos ha demostrado la importancia de esta labor para la comprensión gobal de la secuencia constructiva Simultáneamente debieran solucionarse, en el caso de haberlos obviamente, los problemas relacionados con los revestimientos murales. Después vendrán, si se estimase oportuno, la excavación o los sondeos a efectuar en el subsuelo. Luego la toma de datos, la restitución, el análisis estratigráfico, etc. Evidentemente, cada intervención es un caso concreto con unas circunstancias específicas a las que será preciso adecuar los criterios de actuación.

Un último problema que queremos plantear, por no alargar demasiado este pliego de descargos, es el de la financiación. Aunque en el análisis estratigráfico de las construcciones históricas la calidad de la documentación planimétrica constituya un soporte importantísimo, no siempre resultará posible recurrir a la fotogrametría analítica informatizada, ni conseguir modelos digitales tridimensionales del edificio en el que queremos intervenir. En el caso de San Román de Tobillas, la excepcionalidad del monumento aconsejó la adopción de medidas también excepcionales. San Pedro de Quilchano, en cambio, constituye un ejemplo en el que la limitación de recursos económicos no impidió la consecución đe unos resultados sumamente interesantes, a los que se llegó, sin embargo, con medios mucho más humildes. 


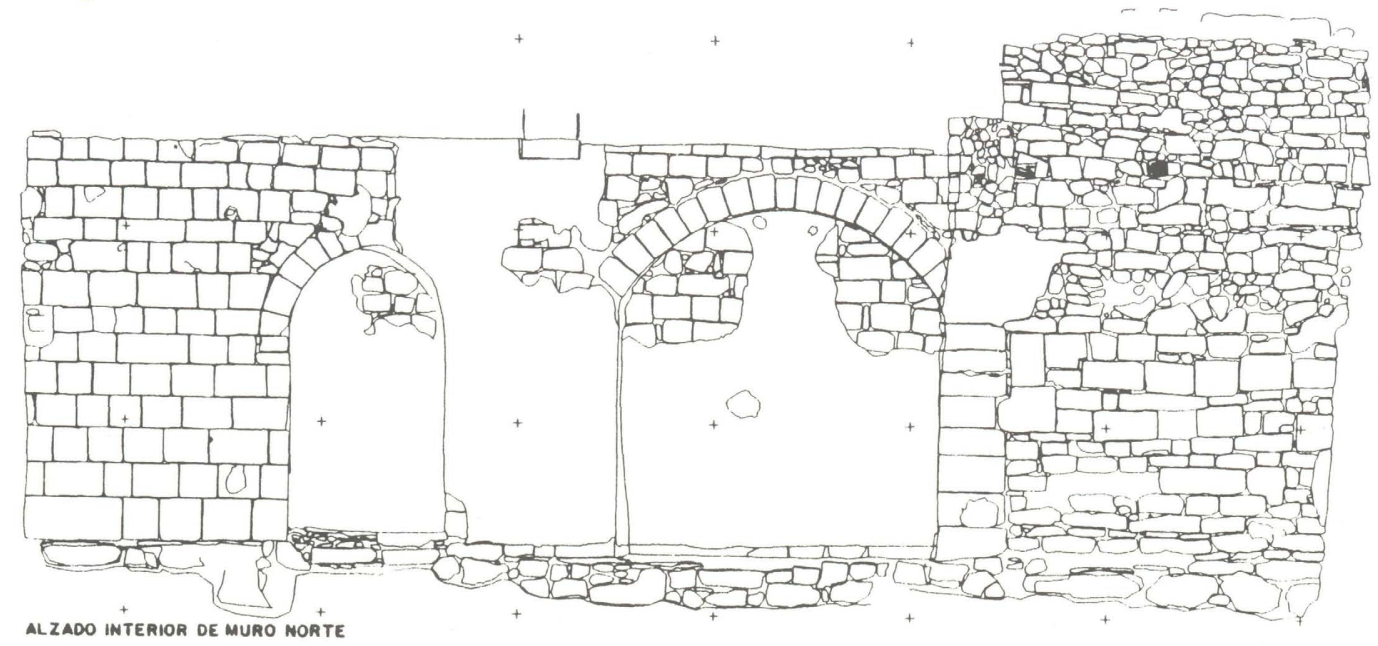

SIGLO XIX

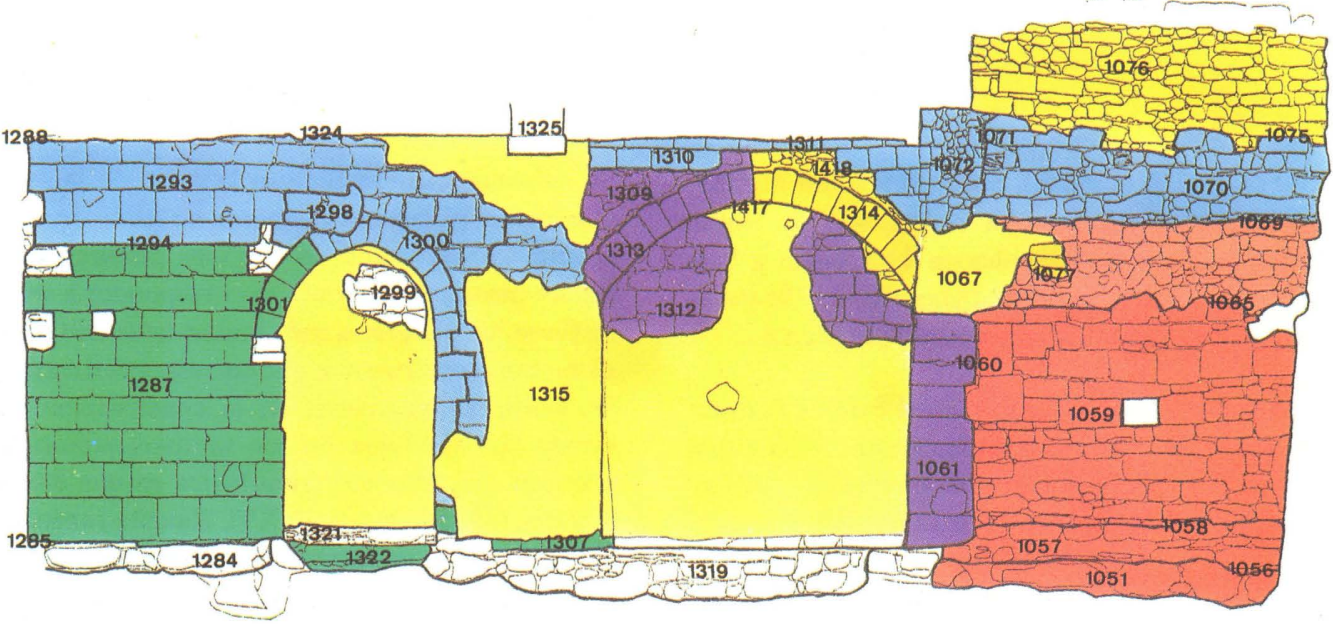

SIGLO XV

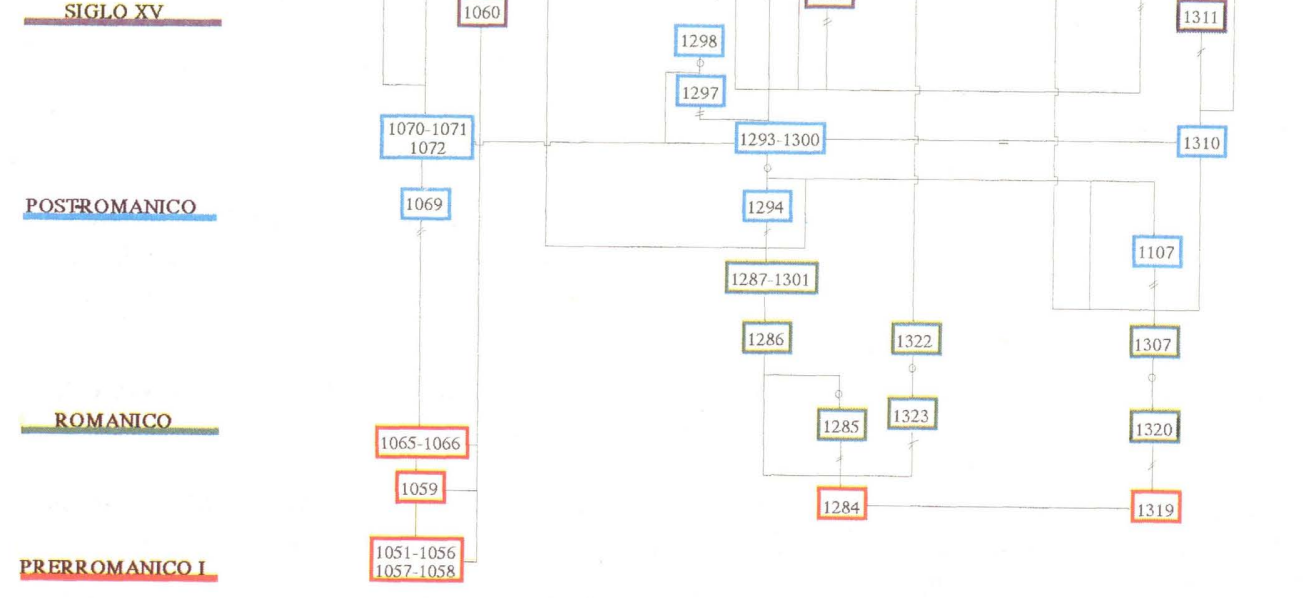

Figs.18a 20.- San Román de Tobillas. Muro interior Norte, alzados y diagrama. 
Abandonando el capítulo -un tanto enojoso- de las dificultades, quisiéramos terminar este breve resumen ponderando las bondades del análisis estratigráfico dell 'edilizia storica . Ya nos hemos referido a ello al considerarlo tanto un instrumento sumamente eficiente para el conocimiento de la historia de la arquitectura y de las técnícas constructivas, como una herramienta eficaz y de indudable valor coadyuvante en los procesos de restauración de nuestro patrimonio edificado. En nuestro caso, ha posibilitado en Tobillas el descubrimiento y análisis pormenorizado de un ejemplar de arquitectura prerrománica de especial relevancia que, de haber sido intervenido con otras "maneras", hubiera pasado totalmente desapercibido sufriendo, quizá, agresiones en su fábrica que la hubieran hecho irreconocible para futuras generaciones. En este punto, sería obligatorio que reflexionáramos todos sobre las intervenciones restauradoras que han podido enmascarar datos de relevancia, atentando irreversiblemente contra nuestro patrimonio arquitectónico. Anteriormente, nos referíamos también al riesgo de caer en generalizaciones abusivas a la hora de adscribir determinados edificios a corrientes artísticas operíodos históricos precisos. La excesiva dependencia que ha habido respecto al valor cronológico de los elementos decorativos, relegando a segundo término los análisis constructivos, es la razón por la que se califique como románica una fábrica que es constructivamente del siglo XVI (San Pedro de Quilchano), o que se ignoren en una iglesia como la del Santo Cristo de Labastida fases constructivas que fueron vitales en la historia del edificio. El análisis estratigráfico llevado a cabo en ambos casos ha permitido corregir estas deficiencias, aportando nuevos datos de carácter histórico y facilitando la labor restauradora de los arquitectos.
${ }^{1}$ L. CABALLERO ZOREDA (Coord.), Sobre el análisis arqueológico de construciones históricas. La experiencia de Santa Eulalia de Mérida, la Torre de Hércules en La Coruña y San Pelayo de Arlanza, III Encuentros sobre Arqueología y Patrimonio de Salobreña. Arqueología del monumento (en prensa).

${ }^{2}$ Un primer avance se publicará, para el caso del Santo Cristo de Labastida y San Pedro de Quilchano, en la revista Arkeoikuska (Vitoria, 1995) y en el próximo número de Archivo Español de Arqueología (Madrid, 1995) para San Román de Tobillas.

${ }^{3}$ Dirección del proyecto de documentación y análisis: A. Azkárate; coordinación de los sondeos arqueológicos y planimetrías: A. Fdz. de Jaúregui y J. Núñez.

${ }^{4}$ Aunque carezcamos de confirmación documental sobre la fecha de su construcción, la tipología de los vanos conservados nos permite ubicarla a finales del siglo XII o comienzos de la centuria siguiente.

${ }^{5} \mathrm{La}$ existencia de una fase prerrománica resulta una simple hipótesis de trabajo que se apoya en la existencia, dentro de la fachada septentrional, de ciertos desalineamientos de la cimentación con respecto al trazado románico que señalan la posible existencia de una zapata fundacional anterior y de orientación diferente.

${ }^{6} \mathrm{La}$ fecha de reconstrucción de la segunda iglesia de Quilchano se deduce de las noticias históricas conservadas. Sabemos, en efecto, que en el año 1337 los habitantes de Quilchano abandonaron el lugar para poblar la nueva villa de Elburgo, fundada por Alfonso XI. Resulta razonable suponer que el esfuerzo de reconstruir una iglesia de notables dimensiones sólo pudo realizarse cuando Quilchano contaba todavía con sus habitantes. Carecería de sentido, por el contrario, hacer frente a una obra de costo notable en un momento en el que el lugar estaba despoblado o en proceso irreversible de abandono. Es por ello, por lo que concedemos a esta reconstrucción una fecha anterior a 1337.
'No sabemos cuándo acaeció la ruina de la segunda iglesia de Quilchano, ni cuándo se aborda su reconstrucción en forma de ermita. Conservamos, no obstante, pinturas murales que resultan de inestimable ayuda para responder a esta cuestión. Los testimonios pictóricos más importantes de Quilchano recubren elementos constructivos que corresponden estratigráficamente a las reformas efectuadas en la construcción de esta primera ermita. La tipología de los motivos pictóricos conservados aconseja su ubicacion cronológica en una fecha que no puede llevarse más allá del siglo XVI. Resulta razonable suponer, por tanto, que las reformas que condujeron a la reducción del perímetro de la segunda iglesia -construida a comienzos del siglo XIV- y su conversión en ermita debieron efectuarse durante el siglo XV o comienzos de la centuria siguiente.

${ }^{8}$ Dirección del proyecto de documentación y análisis: A. Azkárate; coordinación de la excavación arqueológica y planimetrías: A. Fdz. de Jaúregui y J. Núñez.

${ }^{9}$ J. CANTERA ORIVE, Catálogo Monumental de la Diócesis de Vitoria. Rioja Alavesa, I, Vitoria, 1967, p. 195.

${ }^{10}$ E.GARCIA, F.LOPEZ, J.R.DIAZ DE DURANA, Labastida en la Edad Media: poblamiento y organización politico-administrativa (s. X-XIII), Vitoria, 1990, pp. 15-31.

${ }^{11}$ Dirección del proyecto de documentación y análisis: A. Azkárate; coordinación de la excavación arqueológica: A. Fdz. de Jaúregui; fotogrametría: P. Latorre y L. Cámara; asesoramiento: L. Caballero Zoreda.

${ }_{12}$ J. del ÁLAMO, Coleccion Diplomática de San Salvador de Oña, Madrid, 1950, 2 vols. $n^{\circ} 1$.

${ }^{13}$ S. RUIZ DE LOIZAGA, Repoblación y religiosidad popular en el Occidente de Alava (Siglos LX-XII), Vitoria, 1989, 24-26.

${ }^{14}$ CABALLERO ZOREDA, L. et alii, La iglesia prerrománica de S. Pedro el Viejo (Hortigüela, Burgos), Numantia, 5, 139-166. 
${ }^{15} \mathrm{~A}$ pesar de ser arqueólogos quienes firmamos estas líneas, optamos en un principio por titular nuestros proyectos como "análisis arquitectónico" de tal o cual edificio, aún siendo conscientes de las debilidades conceptuales de esta elección. Renunciamos a calificarlos como "análisis arqueológico" por dos motivos más de orden práctico que teórico: en primer lugar, porque lo "arqueológico" posee muchas veces unas connotaciones derivadas de una praxis secular que lo vincula con el conocimiento de la información existente únicamente en el subsuelo -y no era el caso de nuestros proyectos- y, en segundo lugar, porque dichos proyectos estaban gestionados por un Departamento de Arquitectura sin competencias en ámbitos "arqueológicos", dependientes de otro departamento. Tampoco nos decidimos por una denominación no exenta de lógica como la de "análisis histórico". Y ello debido a que lo "histórico" en arquitectura se ha reducido muchas veces a análisis estilísticos o a una simple compilación de circunstancias puntuales (fechas de construcción-reconstrucción-ampliación, referencias a mecenas y benefactores, etc.) que ignoraban, sin embargo, las huellas constructivas dejadas por el tiempo en el propio edificio. Es evidente, empero, que nuestro análisis no agota lo "arquitectónico". No aborda, por ejemplo, cuestiones tan importantes en una restauración como los problemas estructurales $u$ otras patologías derivadas del uso o del impacto urbanistico (cfr. artículo de P. Latorre, L Cámara y L. Caballero,supra).

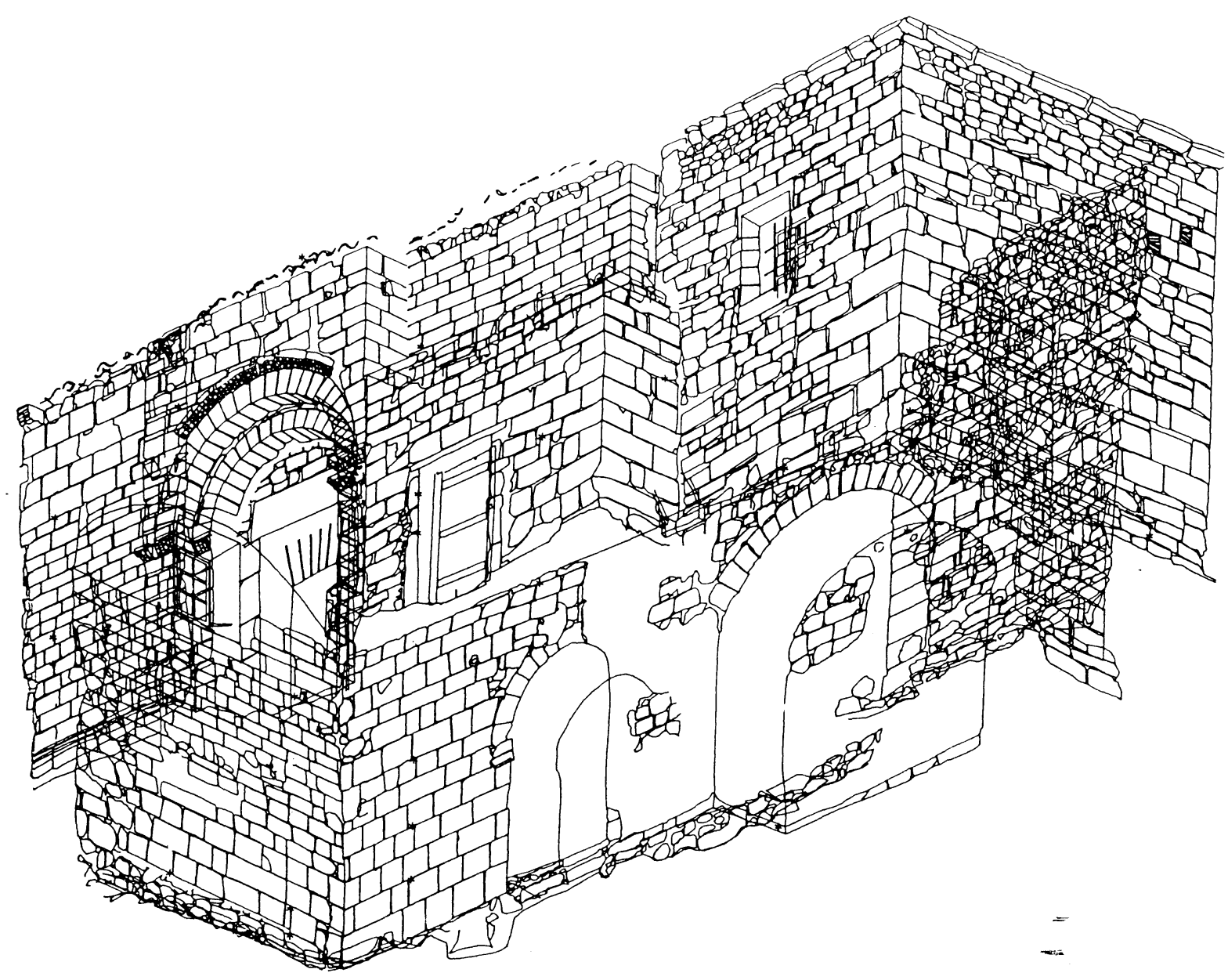

Fig.21.- San Román de Tobillas. Axonometría. 